\title{
KINETICS AND DYNAMICS OF OXIDATION REACTIONS INVOLVING AN ADSORBED CO SPECIES ON BULK AND SUPPORTED PlatinUM aNd COPPER-OXIDE
}

Michael P. Harold, Principal Investigator W. Curtis Conner, Co-Investigator

\section{Department of Chemica! Engineering University of Massachusetts Amherst, MA 01003 $413-545-6143$}

First Year Annual Report Period: $1 / 1 / 91 \cdot 12 / 31 / 91$
DOE/ER/ $13772--4$

DE92 005077

Supported by U.S. Department of Energy Office of Basic Energy Sciences, Chemical Sciences Division (grant no. DE-FG02-87ER!3772)

July， 1991

Project Duration: Three years

Type of Business: Non-profit

Higher Educational Institution
Starting Date: 1/1/91

Budget: $\$ 217,900$

Principal Investigator: Michael P. Harold,

Associate Professor of Chemical Engineering

Co-Investigator:

W. Curtis Conner,

Associate Professor of Chemical Engineering;

Business Contact: Lee D. Beatty,

Director, Office of Grants and Contracts Administration

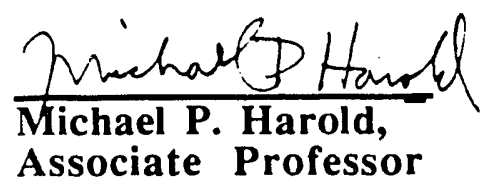

LenQQeatty

Lee D. Beatty, Difector, OOGCA

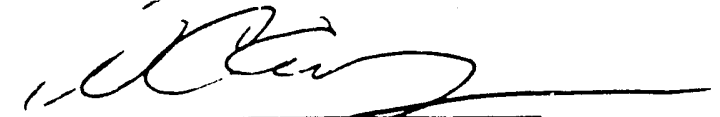

W. Curtis Cormer Associate Professor

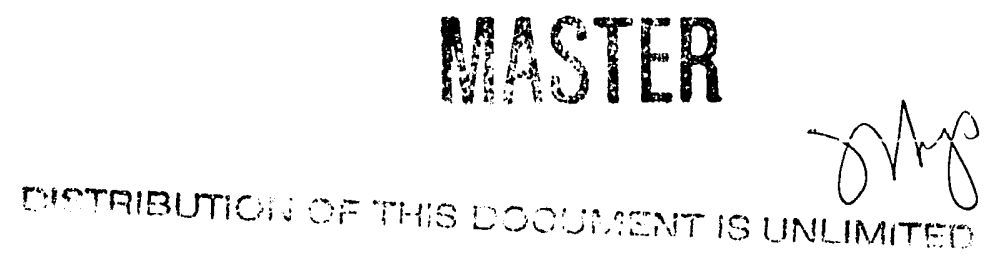




\section{DISCLAIMER}

This report was prepared as an account of work sponsored by an agency of the United States Government. Neither the United States Government nor any agency thereof, nor any of their employees, makes any warranty, express or implied, or assumes any legal liability or responsibility for the accuracy, completeness, or usefulness of any information, apparatus, product, or process disclosed, or represents that its use would not infringe privately owned rights. Reference herein to any specific commercial product, process, or service by trade name, trademark, manufacturer, or otherwise does not necessarily constitute or imply its endorsement, recommendation, or favoring by the United States Government or any agency thereof. The views and opinions of authors expressed herein do not necessarily state or reflect those of the United States Government or any agency thereof. 


\section{Overvicw of the Project}

The proposed research is an integrated experimental and modeling study of oxidation reactions involving $\mathrm{CO}$ as a key player - be it a reactant, adsorbed intermediate, and/or partial oxidation product - in the catalytic sequence and chemistry. The reaction systems of interest in the project include $\mathrm{CO}$, formaldehyde, and methanol oxidation by $\mathrm{O}_{2}$, and $\mathrm{CO}$ oxidation by NO, on both $\mathrm{Pt}$ and copper oxide catalysts. These reactions are of importance in automobile exhaust catalysis. There is a paucity of rate data in the literature for these important environmental control reactions. A complicating factor is the propensity of these reactions to exhibit complex steady state and dynamic behavior, including multiple rate controlling steps, steady state multiplicity, and oscillatory phenomena. Such phenomena are rooted in some of the central issues of catalysis, including adsorbate interactions, and catalyst structural instabilities, such as surface reconstruction and surface chemical changes by oxidation-reduction.

The goal of this research is to better understand the catalytic chemistry and kinetics of oxidations reactions involving $\mathrm{CO}$ as an adsorbed intermediate. Successfully meeting this goal requires an integration of basic kinetic measurements, in situ catalyst surface monitoring, kinetic modeling, and nonlinear mathematical tools. While the kinetics experiments have standard microreactor designs, the potential for multiple and periodic rate states demands detailed procedures to pinpoint the bifurcation (ignition, extinction, Hopf) points. Kinetic models are constructed from rational mechanistic sequences and sound surface chemistry. These models should predict the correct experimentally measured features, including the basic kinetic trends (apparent reaction orders and activation energy), the location and shape of the operating condition region for which the rate is multivalued or periodic, and the trends in the adsorbed state composition. The development of Fourier transform infrared emission spectroscopy (FTIRES) is an essential aspect of the project. FTIRES provides a means of simultaneously monitoring the surface temperature and vibrational spectra corresponding to the adsorbed species and the substrate during a catalytic reaction. FTIRES is used in this research to link such crucidl surface information with the overall kinetics.

\section{Accomplishments During First Year of Project}

In the past year our efforts have focused on three topics which are summarized below.

\section{- Kinetics of $\mathrm{CO}$ oxidation on noble metal catalysts}

In the first stage of this research we have studied $\mathrm{CO}$ oxidation by oxygen on noble metals (primarily Pt) since parts of the mechanistic sequence occur in more complex 
reactions which are our primary interest (e.g., formaldehyde and methanol oxidation). Our main thrust has involved the development of a kinetic modeling methodology for reactions such as $\mathrm{CO}$ oxidation which exhibit multiple rate phenomena. Several models were developed which were able to predict the basic kinetic trends and multiplicity features observed by experimentalists at total pressures spanning UHV to atmospheric. These accomplishments are contained in Journal of Catalysis papers listed below. The same models are being used to better understand the the kinetics of $\mathrm{CO}$ oxidation on $\mathrm{Pt}, \mathrm{Pd}$, and Rh. This is a collaborative effort with Prof. Gary Haller's group at Yale.

Given that $\mathrm{CO}$ oxidation and related reactions are highly exothermic, we have devoted some effort in understanding the impact of the kinetics and thermal effects in experiments which involve ohmic temperature control of unsupported catalysts (e.g., wires, ribbons, foils). We developed a hot wire model comprised of detailed, isothermal Ptcatalyzed $\mathrm{CO}$ oxidation kinetics and the pertinent transport processes. Model simulations were carried out to explain the kinetics data we obtained with our electrically heated Pt wire experiment. We observed rate multiplicity over a wide range of average wire temperatures $\left(\widehat{T}_{w}=100-350{ }^{\circ} \mathrm{C}\right)$, feed compositions $\left(\mathrm{CO} / \mathrm{O}_{2}=0.01-1\right)$, and total pressures $(5-760$ torr). Several of the observed multiplicity features are atypical of conventional isothermal CO oxidation behavior, such as a $\left(\widehat{\mathrm{T}}_{\mathrm{w}}, \mathrm{CO} / \mathrm{O}_{2}\right)$ multiplicity region (bifurcation map) with a local maximum in the extinction branch, which is indicative of a pitchfork singularity. For example, at sufficiently low $\widehat{\mathrm{T}}_{\mathrm{w}}$ and high $\mathrm{CO} / \mathrm{O}_{2}$ an unexpected high rate state was sustained in addition to the expected $\mathrm{CO}$-inhibited, low rate state. Visual inspection of the wire while in the high rate state revealed a glowing hot spot near the center of the wire. We determined that the apparent kinetic anomalies are a manifestation of temperature nonuniformities along a wire of uniform activity and thermal conductivity. The generality of the observed multiplicity features, the observation of hot spots, and the rational model construct suggests that a more complicated kinetic mechanism is not necessary to explain the data. Close similarities between the $\mathrm{CO}$ oxidation data, the simulations, and previously reported data for other Pt-catalyzed oxidations (of propylene and ammonia) suggests that the thermokinetically-induced nonuniformities are a general phenomenon. The results underscore the danger of using ohmic temperature control to study the isothermal kinetics of a metal catalyzed reaction. Model simulations were also carried out to identify conditions for which the impact of nonuniformities can be minimized.

\section{- Development and demonstration of Fourier transform infrared emission spectroscopy}

In the past year we have focused on the general capabilities of FTIRES as a surface characterization tool. A system for in situ analysis of surface reactions using FTIR emission spectroscopy has been developed. It consists of a translatable, flow-through 
emission cell and a paraboloid mirror to collect the emitted radiation. Catalyst surface temperatures up to $500^{\circ} \mathrm{C}$ and total pressures from $10^{-3}-10^{3}$ torr are attainable.

The system was tested by studying the influences of temperature and adsorbate partial pressure on the well-established specura of $\mathrm{CO}$ and $\mathrm{NO}$ chemisorbed on $\mathrm{Pt} / \mathrm{Al}_{2} \mathrm{O}_{3}$. The spectra of chemisorbed $\mathrm{CO}$ are in excellent agreement with data measured independently by the standard IR transmission technique. The spectra obtained when exposing the catalyst to a CO-NO atmosphere reveal bands that are in agreement with previous studies (e.g., linear-bonded CO and isocyanate species). The evolution of th:se bands with varying $\mathrm{CO} / \mathrm{NO}$ ratio in the feed gas are consistent with the established kinetics of Pt-catalyzed CO oxidation. Finally, spectra obtained of an oxidized copper disk reveal peaks corresponding to the two different phases $\left(\mathrm{CuO}\right.$ and $\left.\mathrm{Cu}_{2} \mathrm{O}\right)$ of copper oxide.

Three important factors which influence the spectra quality have been identifie d: background radiation, sample thickness, and metal loading. The emission spectra of samples with insufficient $\mathrm{Pt}$ loading do not give a detectable signal. The emission spectra of samples that are too thick are distorted and difficult to interpret. The latter is caused by self-absorption of emission from within the sample.

These findings are contained in a manuscript to be submitted to the Journal of Applied Spectroscopy.

\section{- Design and construction of methanol oxidation kinetics experiment}

In the past several months we have initiated the design and construction of an experiment to study the kinetics of formaldehyde and methanol oxidation on supported catalysts. We have opted to use supported catalysts (i.e., instead of wires) because of their more practical significance and the occurrence of hot spots on electrically heated catalysts (see above). The experiment consists of a microreactor, flow system, and quadrup sle mass spectrometer. It is designed to permit a rapid collection of rate data over a wile range of cataly'st temperatures and feed compositions. More details of our plans are outlined below.

\section{Plans for the Second Year of Project}

\section{Comparative kinetics study of $\mathrm{CO}$ oxidation by oxygen on $\mathrm{Pt} . \mathrm{Pd}$, and $\mathrm{Rh}$}

Our plan in this part of the project is to simulate $\mathrm{CO}$ oxidation data obtained by Coulston and Haller (Yale). A nonlinear regression scheme will be used to estimate kinetic parameters for the three catalysts. We will compare model estimated activation energies and sticking coefficients to literature values. Our plan is to determine any mechanistic differences for the three metals. 


\section{Kinetics study of methanol oxidation on supjorted Pt catalysts}

Our plan in this part is first to finish construction of the setup and then to collect detailed kinetic data for methanol oxidation on alumina-supported $\mathrm{Pt}$. These steps follow standard procedures. Special attention will be placed on keeping the catalyst isothermal, rninimizing transport limitations, and looking for the existence of rate multiplicity and/or cscillations. These kinetic data will be supplemented by emission IR data to test the validity of certain model assumptions such as the identity and relative surface concentrations of reaction intermediates (e.g., CO, methoxy species). We hope to make IR-spectroscopic measurements of this reaction by the end of the year (i.e., once the CONO study is finished).

After a sufficient amount of data is collected we plan to commence with the formulation of kinetic models. Our approach will follow a methodology similar to the one for $\mathrm{CO}$ oxidation. Ultimately, this step requires the integration of detailed kinetic and surface measurements, sound catalytic chemistry dictated by the established kinetics of elementary steps or groups of steps (e.g., from UHV studies), and modern tools of nonlinear and kinetic analysis permitting the treatment of models having multiple and/or periodic solutions. The initial model formulations will build upon the ideas of $\mathrm{McCabe}$ and coworkers at Ford, who have established similarities in the kinetics of $\mathrm{CO}$ oxidation, formaldehyde oxidation, and methanol oxidation.

\section{Spectroscopic and kinetics study of $\mathrm{CO}-\mathrm{NO}$ on copper oxide catalysts}

This third part of the research will test the full capabilities of the IR emission technique. Our plan is as follows. The kinetics (rates, reaction orders, activation energy) of the NO-CO reaction on a copper oxide catalyst will be investigated using a microreactor (similar to the one to be used in the methanol oxidation experiment). Rates will be measured in the 300-750 $\mathrm{K}$ temperature range for $\mathrm{b} r, \mathrm{~h}$ net-oxidizing $(\mathrm{CO} / \mathrm{NO}<1)$ and netreducing $(\mathrm{CO} / \mathrm{NO}>1)$ reactor feeds. Special attention will be placed on determining the existence of thermokinetic rate multiplicity and/or oscillations. The kinetic data will be used to guide the in situ FTIRES/kinetics studies. The FTIRES spectra will provide vital data on relative surface concentrations of the reactants and changes in the surface oxidation state. One goal is to assess the impact of surface oxidation/reduction on the catalytic activity and selectivity.

Once sufficient data is collected, kinetic modeling for the CO-NO reaction on copper oxide will commence. Particular attention will be focused on several unresolved issucs in the literature, such as the possible existence of more than one rate determining step, the occurrence of rate multiplicity, the role of the adsorbed isocyanate species, selectivity to $\mathrm{N}_{2} \mathrm{O}$ versus $\mathrm{N}_{2}$, and structure sensitivity. A mathematical model will be 
developed for the same reaction carried out on a supported catalyst with two positive valence states (e.g., copper oxide - $\mathrm{Cu}_{2} \mathrm{O}$ and $\mathrm{CuO}$ ) in order to elucidate how the coupling between the redox catalysis and heat and mass transport impact the rate and product distribution.

\section{Graduate Students Participating in this Research}

- Martha Garske - Martha completed here PhD thesis in February, 1991. Her thesis is entitled "Kinetics and Multiple Rate States of Platinum-Catalyzed CO Oxidation. Her project covered most of the aspects of Pt-catalyzed CO oxidation.

- David Sullivan - Dave is in his final year as a PhD candidate. Dave has constructed the FTIRES experiment and is currently studying the kinetics and IR spectra of the CO-NO reaction on copper oxide catalysts. His project is entitled "Kinetics and Dynamics of Carbon Monoxide Oxidation by Nitric Oxide on Copper Oxide Using IR-Emission Spectroscopy."

- Andrew Oliviero - Andrew is completing his first year as a PhD candidate. He is currently building the methanol oxidation experiment.

\section{Publications and Presentations in the Past Year}

\section{Publications}

Harold, M.P., and M.E. Garske, "Kinetics and Multiple Rate States fcr CO Oxidation on Platinum: Model Development and Multiplicity Analysis ," J. Catalysis, 127, 524-552 (1991).

Harold, M.P., and M.E. Garske," Kinetics and Multiple Rate States for CO Oxidation on Platinum: Linking UHV and High Pressure Behavior," J. Catalysis, 127, 553-575 (1991).

Garske, M.E., and M.P. Harold, "Impact of Temperature Nonuniformities on the Kinetics of an Exothermic Reaction on a Temperature-Controlled Catalytic Wire," Chem. Eng. Sci., to appear (1991).

To be submitted:

Sullivan, D., M. P. Iiarold, and W.C. Conner, "Use of Fourier Transform Infrared Emission Spectroscopy as a Surface Analysis Tool," to be submitted to J. Appl. Spectroscopy by August, 1991.

Coulston, G., M.P. Harold, and G. Haller, "A Comparative Kinetic Modeling Study of CO Oxidation on Pt, Pd, and Rh Foils," to be submitted by December, 1991. 


\section{Prosentations}

"Impact of Temperature Nonuniformities on Rate Multiplicity Features During CO Oxidation on an Electrically Heated Wire," presented in 'Chemical Reactor Stability and Dynamics' session, Annual AIChE Meeting, Chicago, 11/90 (with M.E. Garske).

"Surface Analysis with FTIR Emission Spectroscopy," presented in 'General Papers in Catalysis II' session, Annual AIChE Meeting, Chicago, 11/90 (with D. Sullivan (speaker), and W.C. Conner).

\section{Proposed Budget for the Second Year of Project}

The budget proposed for the period 1/1/92-12/31/92 is attached. 

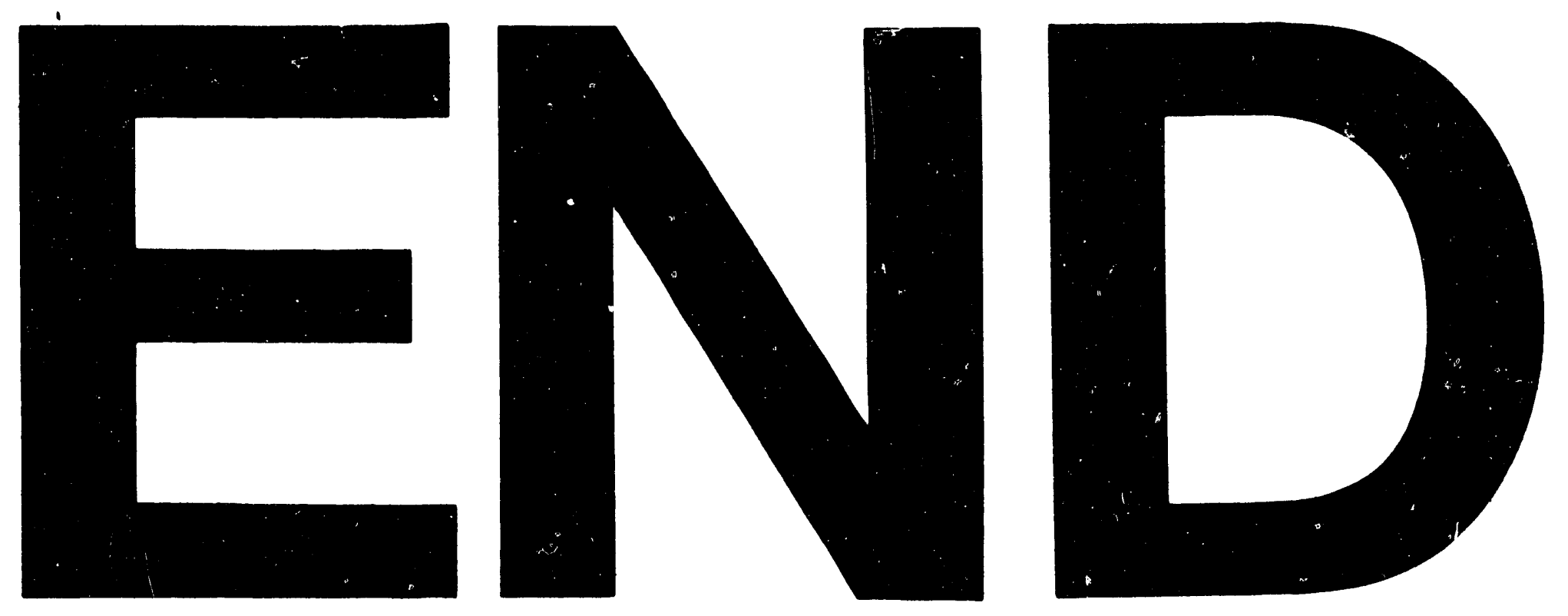

3
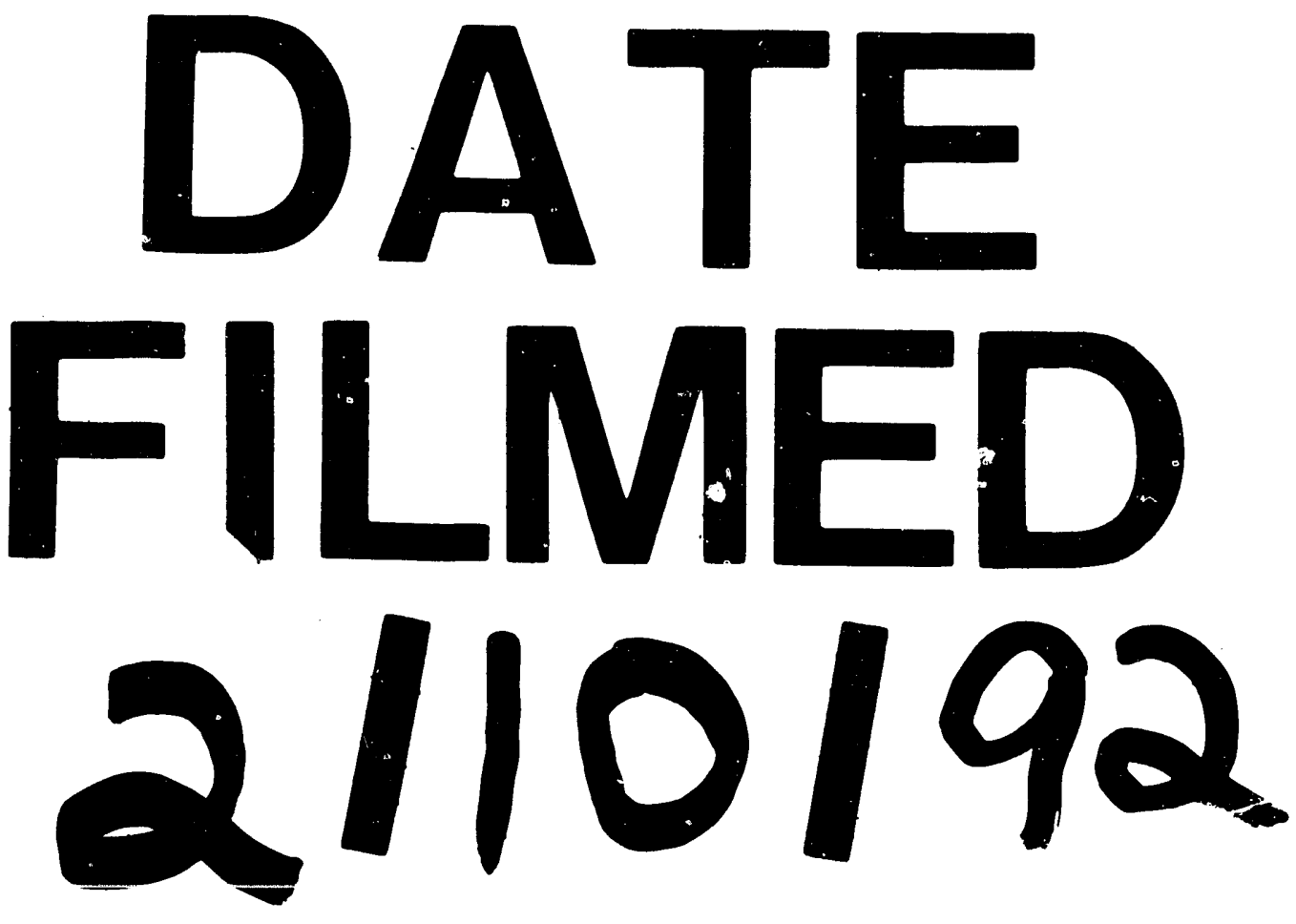


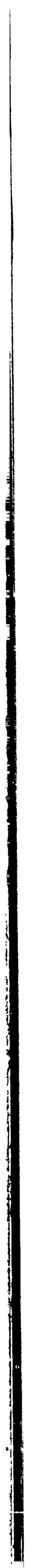

